In the first sample it was noticed that some snow was poured off with the solution to be titrated, which accounts for the large discrepancy. The other tests show fair agreement of the two methods. The accuracy of the thermometer was not tested.

Laboratory work is planned to clear up the problem of liquid water content determination by testing different methods on samples of known water content. It must here be mentioned that dielectric measurements done at the Central Sierra Snow Laboratory by Mr. B. Lyle Hansen (private communication) indicate that the energy of absorption of a water film on ice crystals may introduce an error into calorimetric determinations. This matter will also be investigated.

I 2 April 1950.

Henri BADER (Rutgers University, New Brunswick)

\title{
ICE CRYSTAL OBSERVATIONS ON NORWEGIAN GLACIERS
}

\author{
By Olav LiestöL \\ (Norsk Polarinstitutt, Oslo)
}

IN 1949 my glaciological investigations were mainly confined to Storbreen in Jotunheimen. The work was, however, hindered by the winter snow covering the glacier until early August. The rubbing method of measuring crystal sizes was used and also direct measurement by means of a series of paper circles placed on the ice surface.

The crystal sizes on the rubbings were measured with a planimeter, the mean diameter being calculated by $D=2 \sqrt{\frac{A}{\pi}}$, the method used by Seligman (Fournal of Glaciology, Vol. x, No. 5, p. 254 et seq.). There was great variation in size and distribution of the crystals but there was a gradual increase towards the margins. These observations confirm those of Seligman in Norwegian glaciers.

By means of tunnels following the bedrock some rubbings were obtained at a point $35 \mathrm{~m}$. from the margin and $\mathrm{r}_{5} \mathrm{~m}$. below the glacier surface. The same considerable variation in the size of adjacent assemblages was observed.

Investigations were also made of the orientation of the crystal axes with the aid of a polaroid microscope, and the results will be communicated in due course. By examining crystals in the tongue of Österdalsisen, Svartisen in northern Norway, I found that the direction of the axes in many of the crystals could be ascertained by means of the disc-like air bubbles in the basal plane, thus saving the troublesome microscopic examinations.

In the photograph in Fig. 3 (p. 438) I am holding a large crystal $(36 \mathrm{~cm}$. long) found on the surface in what seemed a refrozen melt hole. I doubt if this refreezing can explain the large crystals found by Seligman (op. cit. p. 266) well below the surface on Storjuvbreen and believe that refreezing can only take place on the surface and a few metres below.

In a tunnel under the snout of Österdalsisen, about $30 \mathrm{~m}$. from the margin where the ice moved over bedrock with a speed of about $5.5 \mathrm{~cm}$. a day I found fine grained ice just above the rock up to $50 \mathrm{~cm}$. Under the microscope it turned out to be fractured ice (of the same type as that which I found last spring in the ice cores from borings on Hardangerjökelen). Later on I found the same phenomenon on the surface along what must be thrust planes. When sufficiently weathered the fractured ice has the macroscopic appearance of snow.* * What may be a similar phenomenon was noted in shear planes and illustrated in Fig. 3 , p. 378 of the $\mathscr{f}$ ournal of
Glaciology, Vol. 1, No. 7.-Ed. 